\title{
SISTEM PENJADWALAN SIDANG TUGAS AKHIR MENGGUNAKAN METODE ANALYTICAL HIERARCHY PPROCESS DI JURUSAN TEKNOLOGI INFORMASI POLITEKNIK NEGERI MALANG
}

\author{
Luqman Affandi 1, Ekojono 2, Rudy Ariyanto 3 \\ 1,2,3 Jurusan Teknologi Informasi Politeknik Negeri Malang \\ 1 laffandi@polinema.ac.id,2 ekojono@polinema.ac.id,3 ariyantorudy@polinema.ac.id
}

\begin{abstract}
Abstrak
Dosen merupakan salah satu civitas akademik yang berperan penting dalam tiga hal sesuai dengan Tri Darma Perguruan Tinggi. Selain itu, dosen juga terlibat pada kegiatan pendukung seperti pembimbing dan penguji pada kegiatan Tugas Akhir di tiap jurusan. Kegiatan ini dikelola oleh Panitia Tugas Akhir, dan salah satu tugas panitia Tugas Akhir yang cukup menyita waktu adalah proses pembuatan jadwal ujian. Proses tersebut pada umumnya dilakukan secara manual dengan menyusun tabel dengan mengisi baris dan kolom menggunakan program perkantoran. Pembuatan jadwal menggunakan program perkantoran seperti MS. Excel sangat menyita waktu, karena harus mencocokkan satu-persatu data antara kolom dan baris apakah ada yang bentrok. Untuk Mengatasi masalah tersebut diperlukan sebuah aplikasi yang menerapkan metode pengambilan keputusan dosen siapa yang cocok untuk dipasang pada jadwal di sesi tertentu. Metode yang dapat digunakan yaitu Analytical Hierarchy Process (AHP) yang membandingkan beberapa kriteria terhadap alternatif yang diberikan. Dari hasil analisis, pengujian dan hasil, metode AHP dapat diimplementasikan dengan baik untuk menentukan dosen penguji di tiap sesi pada jadwal yang ditentukan sesuai dengan kriteria DUK, jumlah sesi, kesesuaian dengan bidang minat dan sebagainya. Hal ini dapat dibuktikan dengan $83 \%$ aplikasi dapat berjalan sesuai dengan harapan. Tingkat efektif dan efisien mempunyai nilai $86 \%$ setelah proses pembuatan jadwal mengimplementasikan metode AHP ke dalam aplikasi.
\end{abstract}

Kata Kunci : Penjadwalan, Analytical Hierarchy Process

\section{Pendahuluan}

Dosen merupakan salah satu civitas akademik yang berperan penting dalam tiga hal sesuai dengan Tri Darma Perguruan Tinggi. Selain itu, dosen juga terlibat pada kegiatan pendukung seperti pembimbing dan penguji pada kegiatan Tugas Akhir di tiap jurusan. Kegiatan ini dikelola oleh Panitia Tugas Akhir.

Salah satu tugas panitia Tugas Akhir yang cukup menyita waktu adalah proses pembuatan jadwal ujian. Proses tersebut pada umumnya dilakukan secara manual dengan menyusun tabel dengan mengisi baris dan kolom menggunakan program perkantoran. Pembuatan jadwal menggunakan program perkantoran seperti MS. Excel sangat menyita waktu, karena harus mencocokkan satu-persatu data antara kolom dan baris apakah ada yang bentrok. Akan menjadi masalah baru jika terdapat perubahan jadwal, proses penyusunan akan dilakukan kembali secara berulang.

Selain itu, untuk membuat penjadwalan tidak mudah dilakukan, karena harus melalui beberapa kriteria yang harus diperhatikan, yaitu dosen penguji harus dari bidang yang sama dengan judul yang diuji, moderator merupakan salah satu pembimbing tugas akhir, penyusunan jadwal harus penyesuaikan
DUK, berapa jumlah ruang yang dipakai dan ada berapa sesi dalam tiap hari. Semua kriteria tersebut harus diperhatikan agar menghasilkan formasi jadwal sidang yang baik, sehingga kegiatan dapat berjalan dengan lancar.

Untuk mengurangi beban pekerjaan panitia khususnya dalam pembuatan jadwal sidang, maka penerapan sebuah metode penentuan pengalokasian dosen ke jadwal berdasarkan kriteria-kreteria tersebut. Metode yang dapat dipakai yaitu Analytical Hierarchy Process (AHP). Dalam penelitian ini membahas bagaimana pengimplementasian metode AHP yang digunakan untuk menentukan dosen yang tepat mengisi jadwal yang sedang disusun berdasarkan kriteria-kriteria yang diberikan, yang diterapkan dalam aplikasi Framework Codeigniter. Untuk mengukur efektif dan efisien implementasi tersebut, penelitian ini mengambil studi kasus di Jurusan Teknologi Informasi Politeknik Negeri Malang.

\section{Metode Penelitian}

\subsection{Teknik Pengumpulan Data}

Untuk mengumpulkan data dilakukan dengan cara observasi dan pengambilan data ke panitia Tugas Akhir Jurusan Teknologi Informasi Politeknik Negeri Malang. 


\subsection{Tahap Pengembangan Aplikasi}

Metode pengembangan aplikasi penjadwalan yang digunakan dalam penelitian ini adalah menggunakan metode siklus hidup sistem/ system development life cycle (SDLC). Metode siklus hidup sistem adalah tahap pendekatan dalam membangun suatu sistem yang membagi pengembangan sistem ke dalam taraf atau tingkat yang ada. Metode SDLC dikenal juga dengan metode waterfall karena setiap tahapan akan menghasilkan keluaran yang digunakan dalam tahapan berikutnya. Dalam penelitian ini, langkah-langkah yang dilakukan seperti terlihat pada gambar 1 berikut:

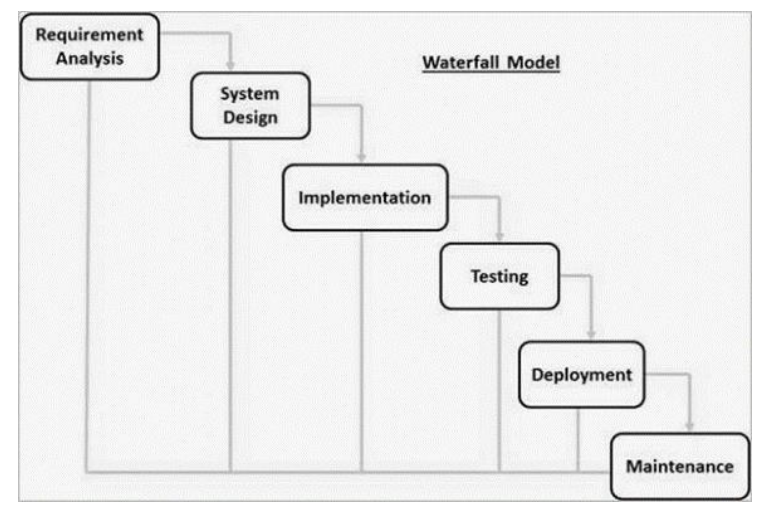

Gambar 1. Waterfall

Pengumpulan Bahan dan Analisis Pada tahap ini dilakukan pengumpulan data dari panitia tugas akhir, meliputi data:

a) Data Dosen, digunakan untuk menentukan dosen yang akan dimasukkan ke dalam jadwal. Data dosen ini meliputi baik dosen yang sudah berstatus Pegawai Negeri Sipil (PNS) maupum kontrak.

b) Data Daftar Urut Kepangkatan (DUK) Dosen, yaitu merupakan ruang dan pangkat yang dimiliki oleh tiap dosen. Data DUK ini digunakan untuk

c) menentukan penguji 1 atau penguji 2 pada penjadwalan sidang tugas akhir.

d) Data keahlian dosen, yaitu daftar dosen beserta keahlian sesuai dengan riset group yang telah dibentuk oleh Jurusan Teknologi Informasi. Data ini

e) digunakan untuk menentukan penguji dengan judul yang dijadwalkan agar sebidang.

f) Data Mahasiswa, yaitu data mahasiswa yang mendaftar sidang pada tahap tertentu, yang selanjutnya digunakan untuk mengisi jadwal yang dibuat.

g) Data pendaftaran ujian, data ini digunakan untuk menentukan siapa saja

h) yang mendaftar ujian pada tahap tertentu, judul apa, siapa pembimbing 1 dan pembimbing 2.

i) Data ruang ujian, didapatkan melalui observasi dan penentuan oleh panitia tugas akhir.
Setelah mendapatkan data yang dilakukan, maka diperlukan analisis terhadap data tersebut serta alur sistem yang telah berjalan dalam pembuatan jadwal sidang tudas akhir. Berikut data yang telah didapatkan:

a) Data Mahasiswa

Data mahasiswa meliputi meliputi

NIM, nama, status_alamat_malang, jenis_kelamin, alamat_orang_tua, no_telp, no_whatsapp.

b) Data pendaftar sidang

Data pendaftar meliputi judul_tugas_akhir, nim, no_pendaftaran, tanggal_daftar, nim_teman_1_group, pembimbing_1, pembimbing_2.

c) Data Kelas

Data kelas meliputi id_kelas, kelas_ujian

d) Data DUK

Data DUK Dosen dapat dilihat pada laman https://forlap.ristekdikti.go.id/ . Pangkalan data dosen berisi tentang NIP, nama, gelar, pendidikan,

jabatan_fungsional,status_ikatan_kerja.

e) Data Keahlian dosen

Data keahlian dosen merupakan peminatan dosen dalam keahlian tertentu, yang dapat dilihat dalam pembagian group riset dosen. Riset group terdiri atas: Sistem Informasi, Computer Vision, Sistem Cerdas, Network, Multimedia dan Game.

Analisis yang dapat dilakukan adalah dengan mengapati proses pembentukan jadwal yang sedang berjalan. Dari proses manual tersebut dapat diadopsi kedalam bentuk aplikasi dengan menerapkan metode AHP. Prosesnya sebagai berikut:

1. Penentuan hari, jumlah sesi, dan jumlah ruangan.

2. Pembuatan tabel jadwal sidang.

3. Pengisian tabel jadwal sidang, dengan alir:

a. Mengutamakan dosen dengan DUK lebih tinggi diupayakan menjadi

b) penguji 1 .

c) Mengupayakan tiap dosen tidak berganti ruangan.

d) Bidang dosen diusahakan sama dengan judul mahasiswa yang diuji.

e) Dosen penguji 1 dan penguji 2 bukan pembimbing.

f) Dosen penguji 1 tidak boleh menjadi dosen penguji 2 .

g) Moderator merupakan dosen pembimbing 1 atau pembimbing 2 .

h) Rata-rata jumlah penguji atau moderator tiap dosen diusahakan sama.

Dari proses tersebut, dapat dikombinasikan dengan metode AHP untuk menentukan dosen siapa yang tepat. Langkah-langkah yang dapat diampil yaitu: 
1. Membuat tujuan dari tiap-tiap permasalahan. Dari proses manual, dapat diambil kesimpulan bahwa tujuan yang akan dicapai sejumlah 7 , yaitu:

a) Mengutamakan dosen dengan DUK lebih tinggi diupayakan menjadi penguji 1. Berikut Hierarki dari point a:

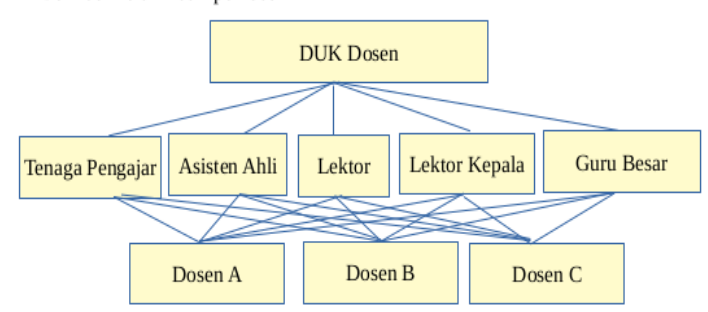

Gambar 2. Hierarki DUKDosen

b) Melakukan perbandingan berpasangan Proses ini merupakan penentuan bobot dari tiap kriteria. Berikut salah satu proses dari tujuan yang telah ditentukan:

\begin{tabular}{|c|c|c|}
\hline & Asisten ahli Lektor & Lektor Kepala Guru Besar \\
\hline Asisten ahli & $1 \frac{11 / 2}{2}(-1)$ & $1 / 3$ \\
\hline Lektor & 2 & $12 / 3$ \\
\hline Lektor Kepala & 3 & $13 / 4$ \\
\hline Guru Besar & 4 & 6 \\
\hline
\end{tabular}

Gambar 3. Perbandingan Berpasangan

c) Hitung bobot kriteria (priority vactor) dengan cara:

- Normalisasi nilai setiap kolom matrik perbandingan berpasangan dengan membagi setiap nilai pada kolom matrik dengan hasil penjumlahan kolom yang bersesuaian.

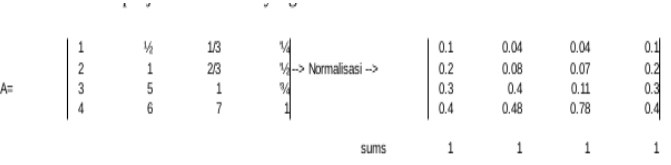

Gambar 4. Normalisasi

- Hitung nilai rata-rata dari penjumlahan setiap baris matrik.

$\left|\begin{array}{rrrr}0.1 & 0.04 & 0.04 & 0.1 \\ 0.2 & 0.08 & 0.07 & 0.2 \\ 0.3 & 0.4 & 0.11 & 0.3 \\ 0.4 & 0.48 & 0.78 & 0.4\end{array}\right| \rightarrow$ Average Vector $\rightarrow \mathrm{X}=\left|\begin{array}{l}0.07 \\ 0.14 \\ 0.28 \\ 0.51\end{array}\right|$

Gambar 5. Rata-rata Vektor

d) Cek Konsistensi rasio (CR)

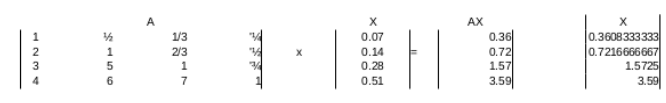

Gambar 6. Cek Konsistensi Rasio

$$
\begin{gathered}
x \max =\operatorname{rata2}(0.36 / 0.36,0.72 / 0.72,1.57 \\
/ 1.57,3.59 / 3.59) \\
=6,254
\end{gathered}
$$

$$
\begin{gathered}
\text { Consistency Index }=(x \max -n)(n-1) \\
=(6,254-4)(4-1) \\
=(2,254 \times 3)=6,735
\end{gathered}
$$

Tabel 1. Tabel IR

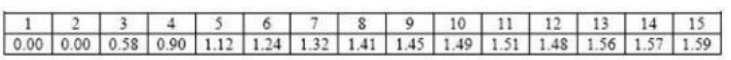

$$
C R=C I / I R=6.735 / 0.9=7.4
$$

Langkah ini dilakukan berulang-ulang sampai didapat nilai dibawah $10 \%$.

e) Pembuatan susunan hierarki baru Dalam langkah ini, dilakukan pembobotan kriteria. Dari perhitunga di atas, maka didapatkan priority vector yaitu:

$$
\begin{gathered}
|0.07| \\
|0.14| \\
|0.28| \\
|0.51| \\
\text { Gambar } 7 \text { Priority Vector }
\end{gathered}
$$

Dengan perhitungan tersebut, maka didapat :

- Bobot Nilai Asisten Ahli adalah 0.07

- Bobot Nilai Lektor adalah 0.14

- $\quad$ Bobot Nilai Lektor Kepala adalah 0.28

- Bobot Nilai Guru Besar adalah 0.51

Langkah berikutnya adalah menghitung bobot tiap alternatf, langkah-langkah yang ditempuh sebagai berikut:

a) Menentukan nilai tiap pilihan/alternatif. Misal: untuk Asisten Ahli

$\begin{array}{lllll}\text { Asisten ahli } & \text { Dosen A } & \text { Dosen B } & \text { Dosen C } & \text { Dosen D } \\ \text { Dosen A } & 1 & 1 / 2 & 0 & 0 \\ \text { Dosen B } & 2 & 1 & 1 / 2 & 0 \\ \text { Dosen C } & 0 & 2 & 1 & 0 \\ \text { Dosen D } & 0 & 0 & 0 & 1\end{array}$

Gambar 8. Perhitungan Alternatif

b) Mengalikan dengan Priority Vector

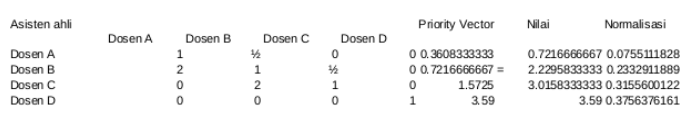

Gambar 9. Perkalian dengan Priority Vector

c) Mendapatkan perengkingan Dari perhitungan tersebut didapat bahwa Dosen D merupakan prioritas utama untuk dijadwalkan, kemudian dosen C, Dosen B dan yang terakhir dosen A. Langkah-langkah tersebut juga dilakukan untuk menentukan Goal/Tujuan yang lain yang telah ditentukan.

\subsection{Desain Sistem}

Agar perhitungan AHP tersebut dapat diimplementasikan kedalam aplikasi, maka diperlukan perancangan desain sistem yang dibangun. Perancangan dalam penelitian ini 
menggunakan pendekatan Object Oriented Design (OOD) karena pemrograman yang dipakai menggunakan Object Oriented Programming. Desain yang dibangun menggunakan UML, dengan rincian pembuatan Use Case, Activity Diagran, dan Class Diagram.

\subsection{Implementasi}

Proses ini adalah pengubahan dari desain ke dalam bahasa pemrograman PHP 7, yang diimplementasikan ke dalam Codeigniter sebagai bahasa pemrograman berbasis Framework. Desain tersebut diimplementasikan juga di dalam database Mysql.

\subsection{Integrasi dan Pengujian}

Proses ini dilakukan untuk menggabungkan aplikasi penjadwalan ke dalam aplikasi tugas akhir yang sudah ada. Integrasi dilakukan melalui dua tahapan yaitu:

a) Tahapan integrasi Codeigniter

Tahapan ini dilakukan dengan cara menambahkan class kelas, class sesi, dam class jadwal di dalam controller aplikasi tugas akhir. Sedangkan di dalam di dalam model, ditambahkan class jadwal yang berisi dua method, yaitu proses_ahp dan generate_jadwal. Untuk menggabungkan tampilan tambahan ke dalam aplikasi tugas akhir, diperlukan penambahan di bagian views dengan file jadwal.php.

b) Tahapan integrasi database

Tahapan ini dilakukan dengan menambahkan 3 tabel tambahan, yaitu tabel kelas, sesi dan jadwal sebagai tabel transaksi.

\subsection{Instalasi Sistem}

Proses instalasi sistem dilakukan dalam dua tahapan, yaitu:

a) Instalasi Web Server dan Database Mysql

b) Instalasi Aplikasi

c) Instalasi Client

\subsection{Pemeliharaan}

Proses ini dilakukan setelah aplikasi dijalankan secara rutin. Pemeliharaan dilakukan dengan bara membackup data secara periodik, dan menghapus data setiap periode angkatan.

\section{Hasil Penelitian}

Hasil yang didapat dari penelitian ini adalah sebuah menu baru di dalam aplikasi tugas akhir yaitu menu ujian, yang berisi jadwal ujian dengan menerapkan pemilihan dosen penguji secara otomatis menggunakan metode ahp. Berikut hasil dari pengembangan aplukasi tersebut:
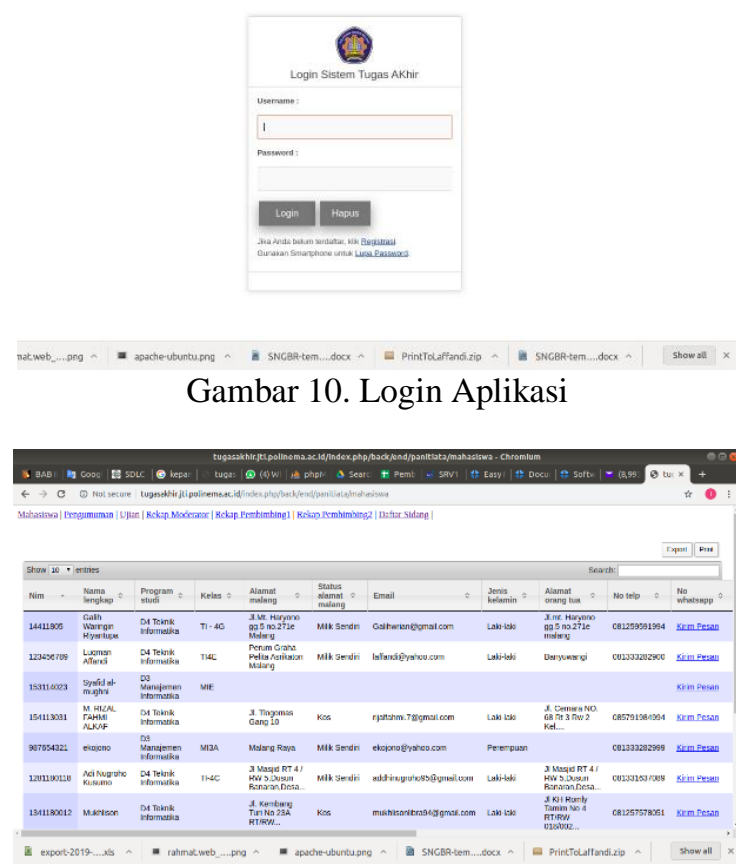

Gambar 11. Menu Aplikasi

Menu panitia terdiri atas mahasiswa, dosen, ujian, rekap moderator, rekap penguji 1, rekap penguji 2, dan daftar sidang.

Proses penjadwalan dapat dilakukan dengan menekan menu Ujian. Sebelum melakukan proses generate jadwal, dperlukan pengaturan kelas dan sesi. Proses generate jadwal menggunakan metode ahp ini memerlukan waktu sekitar 5-10 menit tergantung jumlah data dosen dan mahasiswa yang diolah.

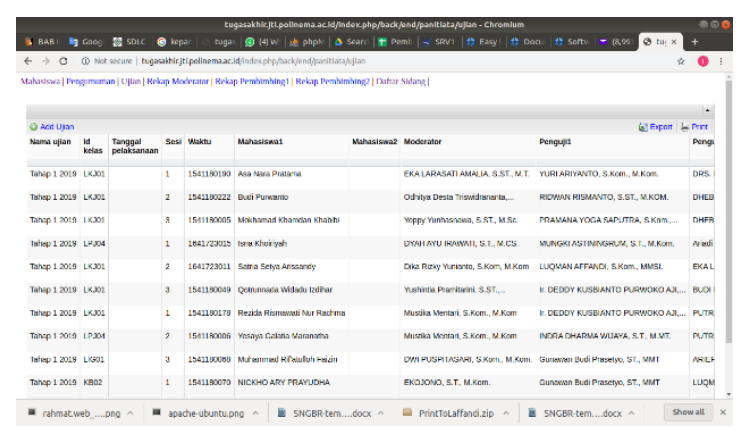

Gambar 12. Menu Jadwal Ujian

Setelah selesai melakukan render, jadwal dapat didownload melalui tombol Export data, dan akan muncul tampilan berikut: 


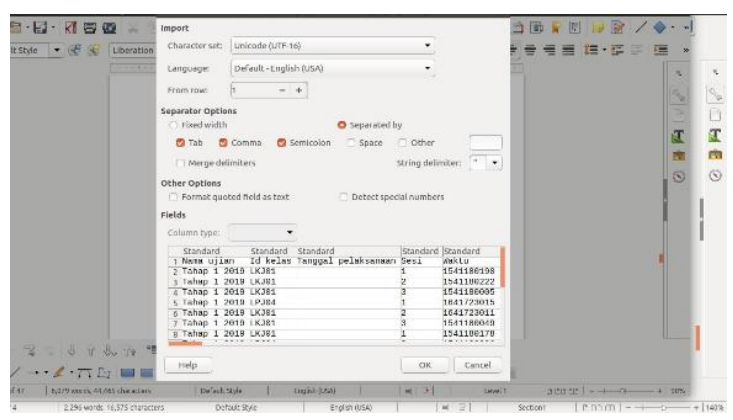

Gambar 13. Proses Download Jadwal Ujian

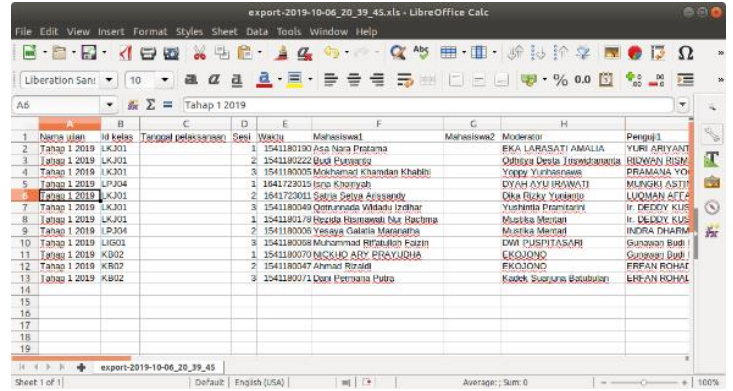

Gambar 13. Hasil Unduhan Jadwal Sidang

Dengan hasil akhir berupa file Excell, panitia tugas akhir dapat mengubah susunan jadwal sesuai keadaan, seperti adanya permintaan jadwal, perubahan jadwal, penggantian jadwal dan sebagainya.

\section{Pengujian Aplikasi}

Untuk menguji apakah aplikasi dan rancangan yang dibuat sudah sesuai dengan harapan, maka diperlukan pengujian Aplha terhadap sistem yangdibangun.

Teknik yang digunakan untuk pengujian menggunakan Black Box Testing, yaitu pengujian berdasarkan masukan dan keluaran yang diinginkan.

Berikut langkah-langkah pengujuain sistem berdasarkan fungsinya:

Tabel 2. Tabel Pengujian Fungsi

\begin{tabular}{|l|l|l|l|l|}
\hline No. & Pengujian & $\begin{array}{l}\text { Hasil Yang } \\
\text { diharapkan }\end{array}$ & $\begin{array}{l}\text { Hasil } \\
\text { Pengujian }\end{array}$ & Kesesuaian \\
\hline 1. & Atur kelas & Berjalan & Berjalan & Sesuai \\
\hline 2. & Atur sesi & Berfungsi & Berfungsi & Sesuai \\
\hline 3. & $\begin{array}{l}\text { Proses render jadwal } \\
\text { menggunakan ahp }\end{array}$ & Berfungsi & Berfungsi & Sesuai \\
\hline 4. & Menampilkan jadwal & Berfungsi & Berfungsi & Sesuai \\
\hline 5. & Mendownload Jadwal & Berfungsi & Berfungsi & Sesuai \\
\hline 6 & $\begin{array}{l}\text { Diimplementasikan } \\
\text { dalam php5 }\end{array}$ & Berfugsi & $\begin{array}{l}\text { Tidak } \\
\text { Berfungsi }\end{array}$ & Tidak Sesuai \\
\hline
\end{tabular}

Dari hasil pengujian tersebut diketahui bahwa 1 dari 6 kriteria pengujian yang dijalankan, memperlihatkan bahwa $83 \%$ aplikasi sudah berjalan, kecuali aplikasi diimplementasin ke dalam versi php yang lebih kecil. Sedangkan untuk mengukur tingkat efektifitas adanya aplikasi, maka dilakukan pengujian Jadwal tersebut selanjutnya dibandingkan dengan jadwal yang dibuat oleh panitia Tugas Akhir secara manual.
Tingkat keberhasilan dapat diukur melalui waktu penyelesaian pembuatan jadwal yang dilakukan oleh panitia Tugas Akhir, sebelum dan sesudah adanya aplikasi.

Dari hasil pengujian yang dilakukan, waktu yang diperlukan dalam pembuatan jadwal tugas akhir tanpa menggunakan aplikasi rata-rata 3 hari, dengan 5 jam efektif. Sedangkan proses yang dihabiskan dalam input data dan proses ahp, melalui pengujian yang dilakukan menghabiskan waktu 2 jam. Sehingga nilai efisien dari adanya aplikasi tersebut yaitu $86 \%$.

\section{Kesimpulan dan Saran \\ 6.1 Kesimpulan}

Dari hasil analisis, pengujian dan hasil, dapat disimplukan bahwa:

1. Metode AHP dapat diimplementasikan dengan baik untuk menentukan dosen penguji di tiap sesi pada jadwal yang ditentukan sesuai dengan kriteria DUK, jumlah sesi, kesesuaian dengan bidang minat dan sebagainya.

2. Tingkat efektif dan efisien mempunyai nilai $86 \%$ setelah proses pembuatan jadwal mengimplementasikan metode AHP ke dalam aplikasi.

\section{Saran}

Untuk meningkatkan keakuratan penjadwalan, perlu dilakukan penambahan kriteria seperti permintaan jadwal khusus, dosen yang berhalangan hadir, dan kriteria dari mahasiswa seperti ijin, sakit atau yang lain.

\section{Daftar Pustaka:}

Danang, Iman Saufik Suasana, 2013, "Pengaturan Jadwal Kuliah Multi Kampus Dengan Metode AHP Berbasis Web"

Heru Nurwarsito, 2009, "Sistem Informasi Jadwal Perkuliahan dengan Metode Sistem Pakar", Jurnal EECCIS Vol. III No. 1

Aji Sasongko, 2017, "Pemilihan Karyawan Baru Dengan Metode AHP (Analytic Hierarchy Proscess)", Jurnal Informatika Mulawarman Vol. 12, No. 2

Nurdi, 2012, "Penjadwalan", Modul Perkuliahan.

Liza Yulianti, 2013, "Implementasi Jaringan Syaraf Tiruan Dalam Sistem

Pendukung Keputusan (SPK) untuk Memilih Perguruan Tinggi”, Jurnal Media Infotama, Vol.9, No.2.

Syaifullah, 2010, "Pengenalan Metode AHP", Artikel Ilmiah www.codeigniter.com, diakses tanggal 26 Agustus 2019, pukul 20.10 
Volume 6, Edisi 4, Agustus 2020

36 | H a 1 a $m$ a n 